\title{
Introduction
}

\author{
John R Hughes
}

\author{
University of \\ Vermont Human \\ Behavioral \\ Pharmacology \\ Laboratory, \\ Burlington, Vermont, \\ USA \\ J R Hughes
}

Our next presenters will be discussing several of the implications of the different kinds of harm reduction. Then we shall have the reactions of our panelists. Let me introduce our presenters and panelists.

Our first presenter is Neal L Benowitz who is going to talk about medical implications of harm reduction. Dr Benowitz is professor of medicine, psychiatry, and pharmacology and chief of the division of clinical pharmacology and experimental therapeutics at the University of California-San Francisco. His research has focused primarily on human pharmacology and toxicology of nicotine.

Our next speaker is Judith K Ockene who is going to review the public health implications. Dr Ockene is a professor and director of the division of preventive and behavioral medicine in the department of medicine, University of Massachusetts Medical School. Her major research has been in the area of physician education and developing counselling skills for interventions.

Our third speaker is Kenneth E Warner. He will address the financial implications of harm reduction. Dr Warner is the Richard D Remington Collegiate Professor of Public Health and chair of the department of public health policy and administration at the University of Michigan School of Public Health. His research has focused on the economic and policy aspects of disease prevention and health promotion, with a special emphasis on smoking and health.

\section{Medical implications}

\author{
Neal L Benowitz
}

In relation to the medical aspects of harm reduction, two medical issues are of concern: (1) Do harm reduction strategies reduce the medical complications of tobacco use? (2) Are the treatments used to promote harm reduction in themselves harmful; which is analogous to the question - does the harm reduction policy cause harm?

I shall deal with these two general issues in the context of four treatment scenarios: (1) nicotine replacement or any other treatment with the goal of reducing cigarette consump-
Next is Charles W Gorodetzky. Dr Gorodetzky is therapeutic area vice president for CNS in the clinical research department at Marion Merrell Dow, Inc. He worked at the National Institute on Drug Abuse Addiction Research Center in Lexington, Kentucky, and was Director of that laboratory from 1979 to 1984. One of his first efforts at Marion Merrell Dow was - and this shows you what we are battling with - to convince them that nicotine actually was a central nervous system drug and should be moved from general medicine to the CNS.

Our panel has three members. The first is John C Ball, who is a professor in the department of psychiatry at the University of Maryland School of Medicine. I know Dr Ball mostly for his pioneering work in showing that methadone decreases HIV positivity, and he has battled for looking at harm reduction with opioid dependents.

Next we have Carl C Peck, who is director of the Center for Drug Development Science at the department of pharmacology at Georgetown University. He was director of FDA's Center for Drugs where he took an active role in nicotine replacement therapies.

Our last panelist is Stephen I Rennard. He is Larson professor of medicine and chief of the pulmonary and critical medicine section at the University of Nebraska Medical Center. He was also one of the authors on the slides I showed you looking at reduction strategies. $\mathrm{He}$ did some of the first research where the goal was reduction instead of cessation.
Division of Clinical Pharmacology and Experimental Therapeutics, University of Francisco, Box 122 San Francisco, CA 94143-1220, USA NL Benowitz

Correspondence to: Neal L Benowitz MD tion; (2) nicotine maintenance to support tobacco abstinence; (3) over-the-counter nicotine availability; and (4) physical modification of cigarettes to reduce the adverse health consequences of smoking. I shall discuss efficacy and safety for each strategy.

Cigarette consumption and disease risk The first general area is nicotine replacement, with a goal of smoking fewer cigarettes. The first question is, does smoking fewer cigarettes 